\title{
The Effect of Hydrazide group on the oxydation of ferrocene at two different electrodes using Rotating Disk Electrode (RDE) in organic medium
}

\author{
Salah Neghmouche Nacer, Touhami Lanez* \\ VTRS Laboratory, University of El Oued, B.P. 789, El Oued 39000, Algeria \\ *E-mail address: nasersaleh78@yahoo.fr
}

\section{ABSTRACT}

Through this work we adopted Rotating Disk Electrode (RDE) kinetics of oxidation and the effect of hydrazide group on ferrocene in org hedium. Thus, two different electrodes ( $\mathrm{Pt}$ and $\mathrm{Ge}$ ) were used in order to determine this 1 cer. Acco $\mathrm{g}$ to to ferrocene taken as a witness the hydrazide group related to the ferrocene $\mathrm{m}$-xidation difficult. This ferrocenic derivative showed an electrochemical stability, a reve ible trochemid al system and an electronic attractor effect of these substitutional ferrocene coups. F, ve calculated some electrochemical parameters which were: the diffusion o efficients (D), thy ayer thickness $\langle\boldsymbol{\delta}\rangle$ in addition to the electron transfer rate.

Keywords: Rotating Disk Electrode (RDE); diffusion potential; Randles-Sevcik equation

\section{INTRODUCTION}

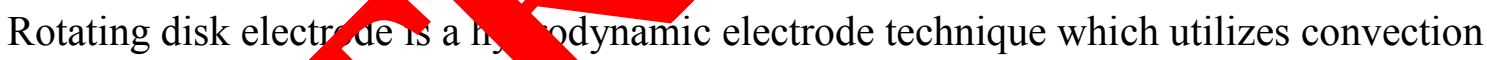
as the mode of mass port as of to $\mathrm{CV}$ which is governed by diffusion. Thus a comparison of the $\mathrm{k}$ etic $\mathrm{p}$ meters ebtained from $\mathrm{CV}$ and RDE experiments is informative to elucidate the r mass the nort on electrode reaction kinetics.

In kineti studi of electr a processes, uniformity of the concentration gradients along the electrod face and $q$ antitative information concerning these gradients are necessary. In many instances rotatin, disk electrode technique provides an effective means for realizing these $\mathrm{cq}_{\mathrm{w}}$ ments nermore this technique allows the surface concentration of reactants an rodu s to be aried in a controlled manner through changes in the rotation rate and hence to determine the reaction orders through the dependence of the current on the rota rate without the necessity of varying the bulk concentrations.

Man studies and analysis by electrochemical methods were effected on the oxidoreducing properties of ferrocene. In general, the cathodic behavior ferrocene in an organic media such as dichoromethane, acetonitrile and DMF can be described by a reversible reduction in an electron, leading to ion Ferrocerium [1,2]. In the present work the oxidation of ferrocene, $\mathrm{Fe}\left(\mathrm{C}_{5} \mathrm{H}_{5}\right)_{2}$, to the ferrocenium cation, $\mathrm{Fe}\left(\mathrm{C}_{5} \mathrm{H}_{5}\right)_{2}{ }^{+}$, was examined in the solvent dichloromethane solution containing tetrabutylammonium tetrafluoroborate, using RDE. The results indicated that redox reactions of ferrocene/ ferricenium couple were a reversible 
process of diffusion-controlled single electron transfer in the studied solution. One of the ferrocene derivatives the compound N'-Ferrocenylmethyl-N'-henylbenzohydrazide is a very important electron-transfer system for molecular electronics owing to its characteristic redox behaviors [6-5], and it could also be expected to play a key role of an electron chemical probe of the electron-transfer process in biological molecules $[7,8]$.

It is well known that N'-Ferrocenylmethyl-N'-Phenylbenzohydrazide easily undergoes one electron oxidation to form ferrocenium cation in a reversible manner [9,10] Figure 1. Thus, we investigated the electrochemical N'-Ferrocenylmethyl-N'-Phenylbenzohydrazide behaviors in organic media.
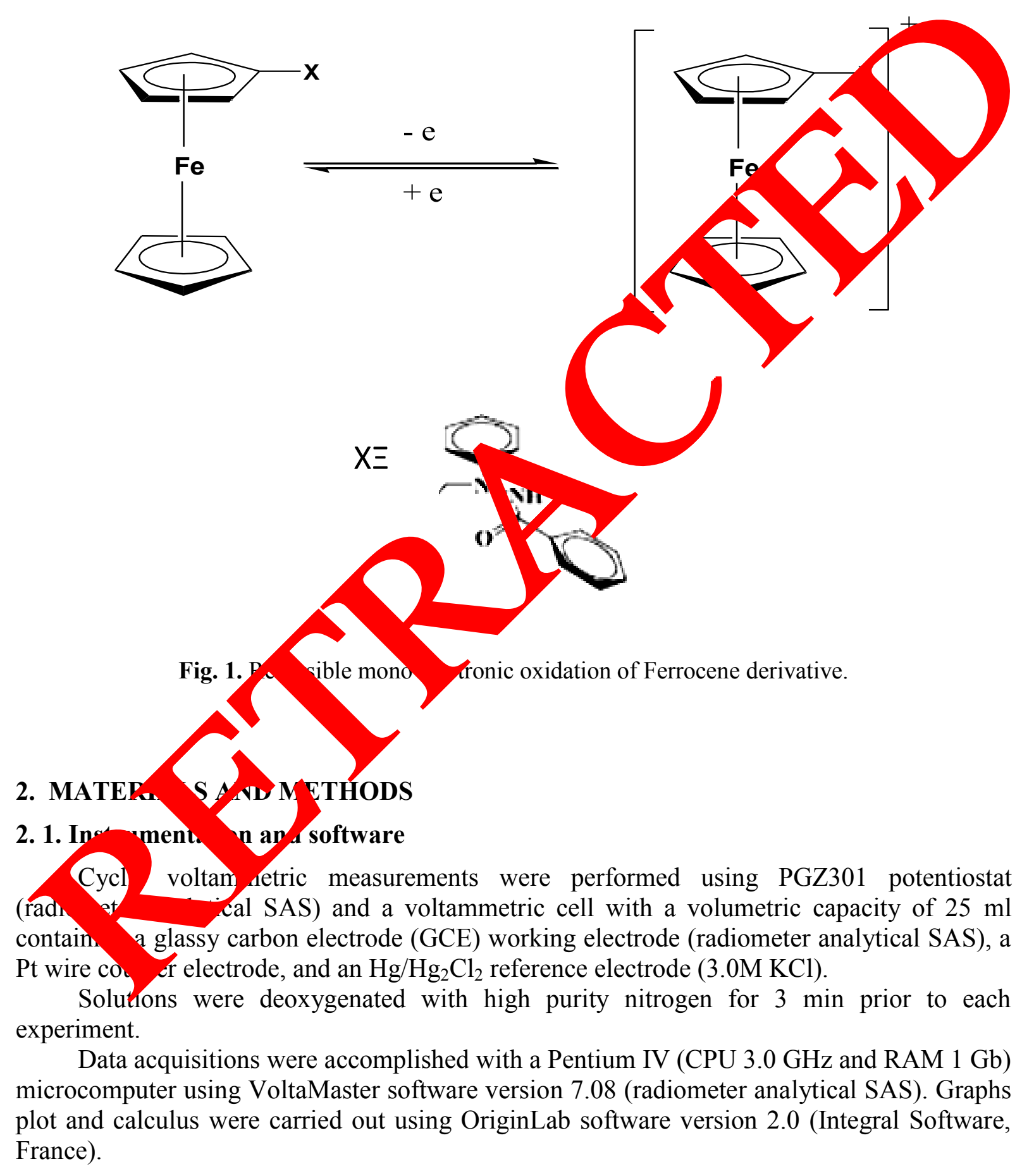


\section{2. Chemicals}

Electrochemical characterization was carried out on a potentiostat type voltalab 40 of radiometer, with a three-stand electrode cell.

Cyclic voltammetric experiments were performed in deoxygenated $\mathrm{CH}_{2} \mathrm{Cl}_{2}$ solution of $\mathrm{N}^{\prime}$-Ferrocenylmethyl-N'-Phenylbenzohydrazide with respectively $10^{-1} \mathrm{M}$ of $\mathrm{Bu}_{4} \mathrm{NBF}_{4}$ as supporting electrolyte and N'-Ferrocenylmethyl-N'-Phenylbenzohydrazide concentration of $10^{-3} \mathrm{M}$. The three electrodes used were glassy carbon and Platinium disk as the working electrodes, saturated calomel electrode as a reference electrode, and Pt wire as an auxiliary electrode. The working electrode was polished with $0.05 \mu \mathrm{m}$ alumina slurry for 1-2 minutes, and then rinsed with double-distilled and deionized water. This cleaning process is done before each cyclic voltammetry experiment.

\section{RESULTS AND DISCUSSION}

The N'-Ferrocenylmethyl-N'-Phenylbenzohydrazide was sy siz a ace romg to literature procedures [7]. Fig. 2, 3 a shows RDE Polarogram to inrocen and N'Ferrocenylmethyl-N'-Phenylbenzohydrazide at a series of rota rates. It ront from the data that the current generated by the RDE method is muc lars than that enerated under diffusion control. The much larger current that was bained $\mathrm{ng}$ RE, reflects the efficiency of this method.

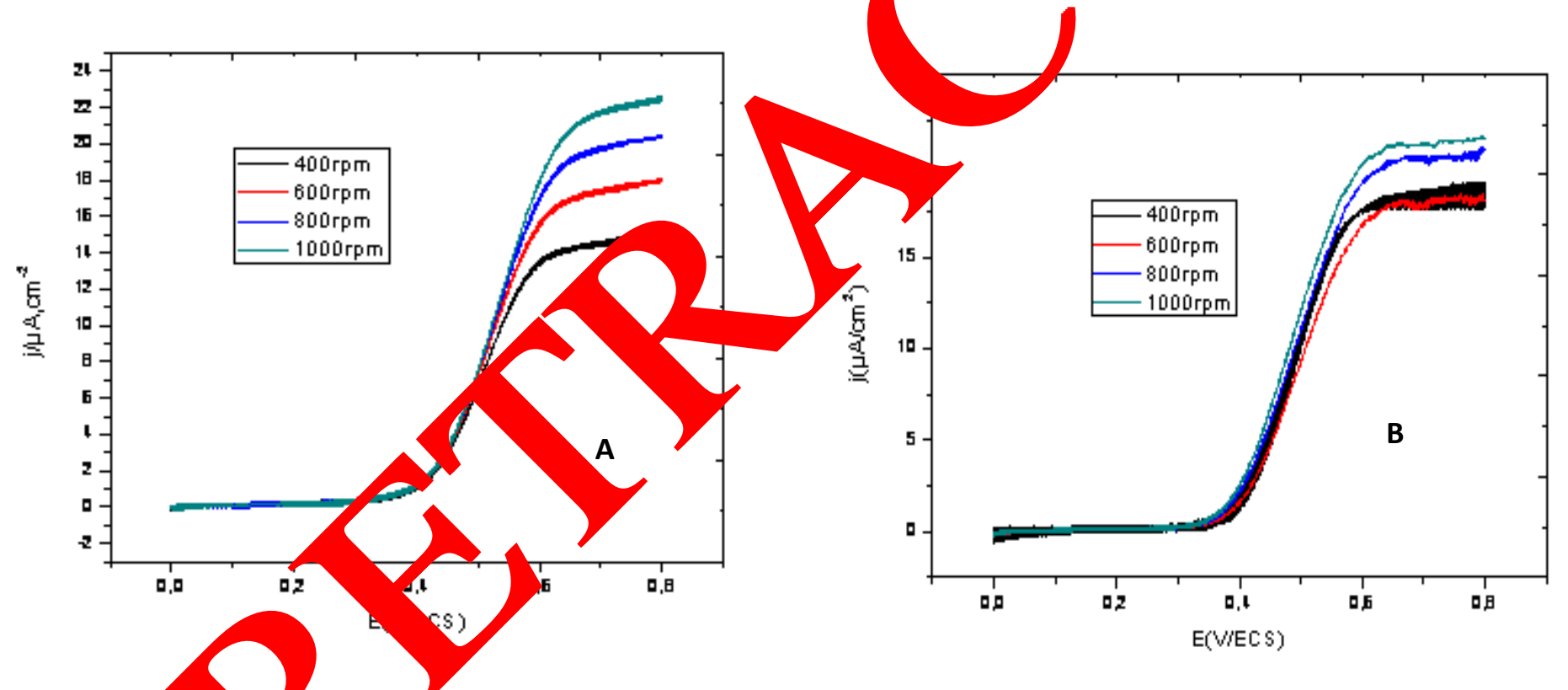

Fì $\mathbf{A}, \mathbf{D})$ larogramme of $1 \mathrm{mM}$ Ferrocene and $100 \mathrm{mM} \mathrm{Bu} \mathrm{NBF}_{4}$ in $\mathrm{CH}_{2} \mathrm{Cl}_{2}(\mathrm{~A})$ at glassy carbon th ing electrode (B) at platinium working electrode, Pt counter electrode, and CSE reference electrode at $0.50 \mathrm{~V} \cdot \mathrm{s}^{-1}$ (Rotating rate $\left.400,600,800,1000 \mathrm{rpm}\right)$. 

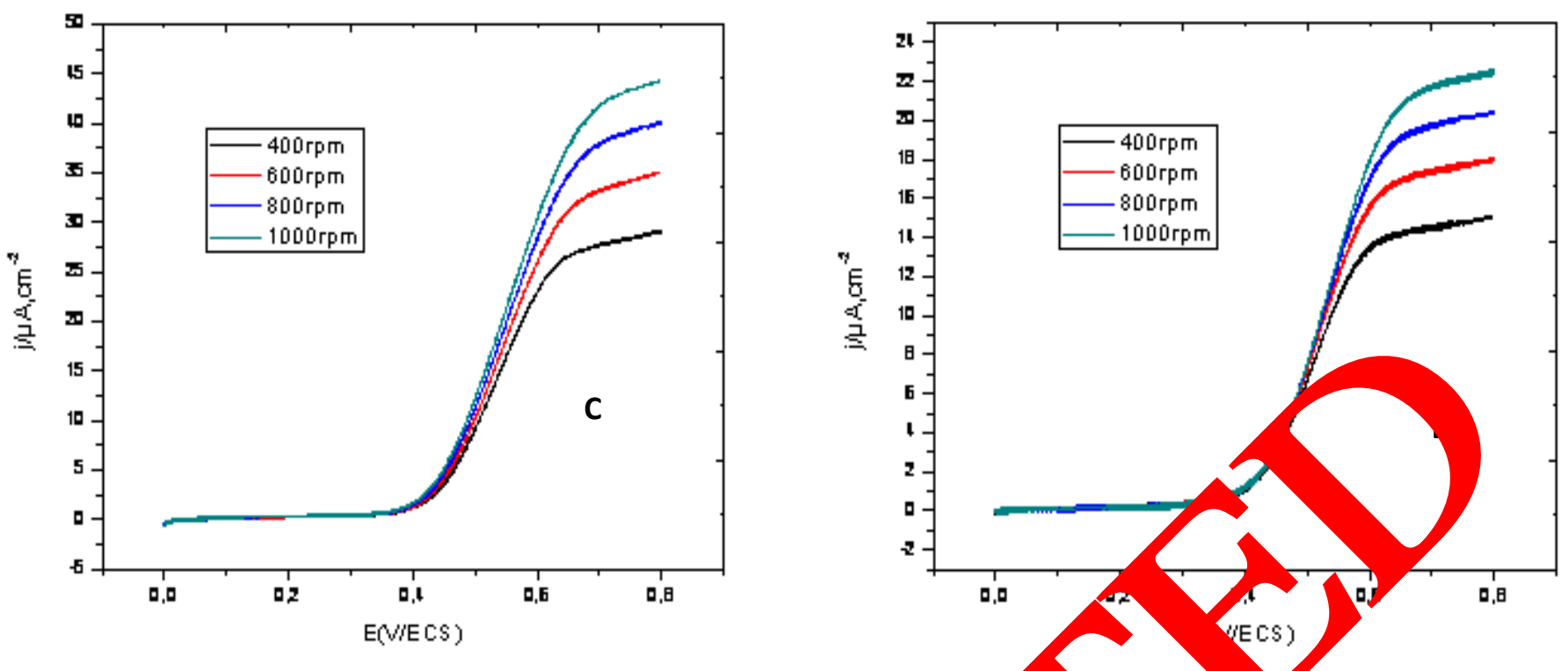

Fig. 3 (C, D). Polarogramme of $1 \mathrm{mM} \mathrm{N}$-Ferrocenylmethyl-N'- reny zohydraz) ae and $100 \mathrm{mM}$ $\mathrm{Bu}_{4} \mathrm{NBF}_{4}$ in $\mathrm{CH}_{2} \mathrm{Cl}_{2}$ (A) at glassy carbon working electrode at platin working electrode, $\mathrm{Pt}$ counter electrode and CSE reference electrode at $0.50 \mathrm{~V} \cdot \mathrm{c}$ (Rotating rate $4 \mathrm{y}$,600, 800, $1000 \mathrm{rpm}$ ).

The diffusion current limit, the current half-wa and half wave potential are calculated at different rotation speed of the two electro ${ }^{-1}$ Table

Table 1. Electrochemical parameters calculated rop por gammes obtained at glassy carbon and platinium electrodes of different $r$ ational speed in organic medium.

\begin{tabular}{|c|c|c|c|c|c|}
\hline \multirow{2}{*}{ Electrode } & & & & \\
\hline
\end{tabular}




\section{1. Calculation of diffusion coefficient}

The Levich equation predicts the current observed at a rotating disk electrode and shows that the current is proportional to the square root of rotation speed. The equation is:

$$
\delta=0.645 D_{0 x}^{\frac{1}{3}} \gamma^{\frac{1}{2}} \omega^{-\frac{1}{2}}
$$

Where $\mathrm{D}_{\mathrm{ox}}$ : diffusion coefficient of the oxidant is expressed in $\mathrm{cm}^{2} \cdot \mathrm{s}^{-1}$

$\omega: \quad$ rotational speed of the electrode $\left(\mathrm{rad} \mathrm{s}^{-1}\right)$

$\gamma$ : kinematic viscosity in $\mathrm{cm}^{2} \cdot \mathrm{s}^{-1}$

Kinematic viscosity: is the ratio of the viscosity on the density, we have viscosity $=0.43 \mathrm{mPa} \cdot \mathrm{s} 25{ }^{\circ} \mathrm{C}$

density $\mathrm{d}=1.328$

$$
\begin{aligned}
& \gamma=\frac{0.43}{1.328} \cdot 10^{-3} \frac{\frac{\mathrm{kg}}{\mathrm{m} \cdot \mathrm{s}}}{\frac{\mathrm{kg}}{\mathrm{m}^{3}}}=0.323 \cdot 10^{-3} \frac{\mathrm{m}^{3}}{\mathrm{~m} \cdot \mathrm{s}}=0.3 \cdot 10 \\
& =0.0323 \mathrm{~cm}^{2} \cdot \mathrm{s}^{-1} \\
& \gamma=0.0323 \mathrm{~cm}^{2} \cdot \mathrm{s}^{-1}
\end{aligned}
$$

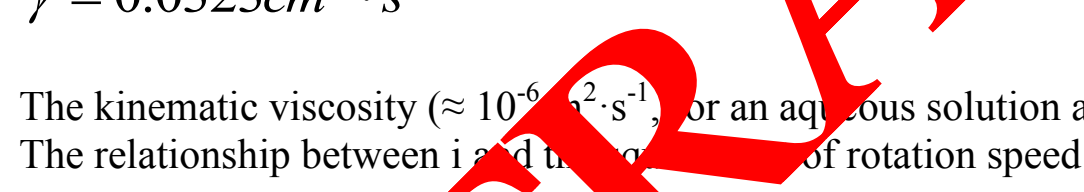

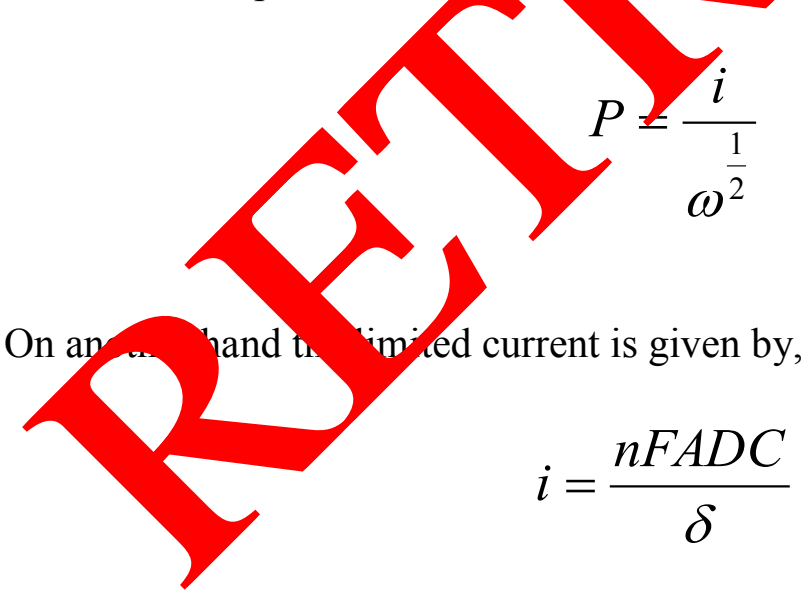

where as: n, number of electrons

$\mathrm{F}$ : is the Faraday $\left(9.65 \cdot 10^{4} \mathrm{C} / \mathrm{mol}\right)$

A: is the area of the working electrode $\left(\mathrm{cm}^{2}\right)$.

$\mathrm{D}$ : is the coefficient diffusion $\left(\mathrm{cm}^{2} \cdot \mathrm{s}^{-1}\right)$

$\mathrm{C}$ : is the concentration $\left(\mathrm{mol} / \mathrm{cm}^{3}\right)$, in our case is equal to $10^{-3} \mathrm{~mol} / 1$ 
Replacing equations 2 and 3 in 4 gives,

$$
D^{\frac{2}{3}}=\frac{P 1.61 \gamma^{\frac{1}{6}}}{n F A C \sqrt{2 \pi}}
$$

\section{2. Applications}

For a rotating rate of the working electrode equal to $400 \mathrm{t} / \mathrm{min}$., the coeffici nt dift of N'-Ferrocenylmethyl-N'-Phenylbenzohydrazide in dichlormethane is.

$$
D=9.78 \cdot 10^{-6} \mathrm{~cm}^{2} \cdot \mathrm{s}^{-1}
$$

The coefficient diffusion of ferrocene in aqueous ethanol $s$ culcu $\mathrm{d}$ as ab ve. Table 2 summarize the obtained values.

Table 2. Diffusion coefficients of compoud calculated polaro nme of Figure 3.

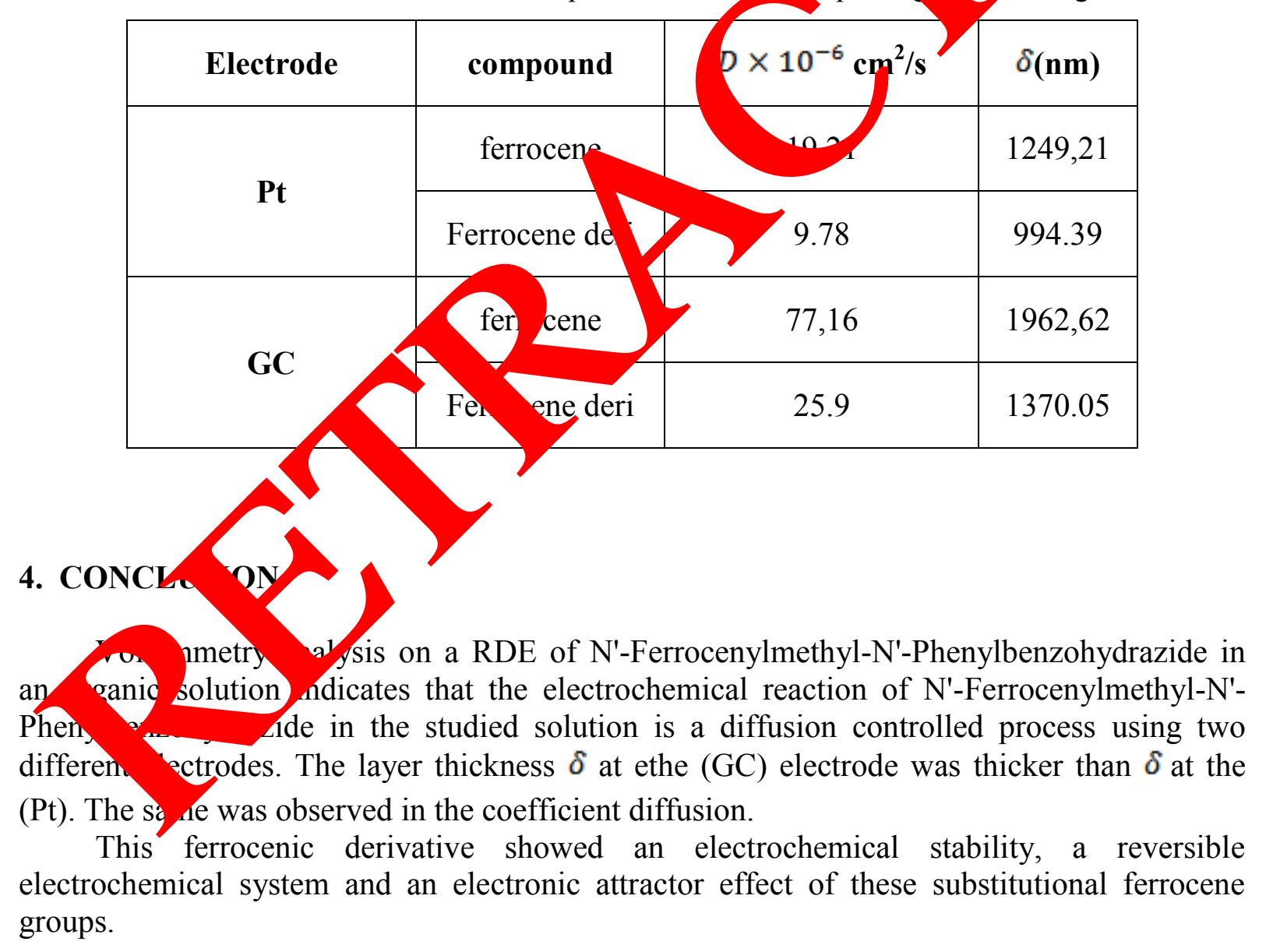




\section{ACKNOWLEDGMENTS}

The authors gratefully acknowledge Mr A. Khelef Maitre assistant at The University of El Oued for his help and advice, and the Technical staff in the laboratory of VPRS for its support.

\section{References}

[1] Gritzner G., Pure Appl. Chem. 56 (1984) 461.

[2] Page J. A., Wilkinson G., J. Am. Chem. Soc. 74 (1952) 6149.

[3] Kealy T. J., Pauson P. L., Nature 168 (1951) 1039.

[4] Khelef A., Neghmouche N. S., Lanez T., Rev. Sci. Fond. App. 3(2)

[5] Terki B., Chérifi N., Lanez T., Belaidi S., Asian J. Chem. 18(3) (2r 66$)$

[6] Neghmouche N. S., T. Lanez, International Letters of Chemis $P$ 4 (2013) 37-45.

[7] Osgerby J. M., Pauson P. L., J. Chem. Soc. (1958) 642

[8] Perrin D. D., Armarego W. L. F., Purification of lo joranry Chem
New York 1988.

[9] Neghmouche N. S., Khelef A., Lanez T., Rev. S Fond. App 1(1) (2009) 23-30.

[10] Neghmouche N. S., Khelef A., Lanez RJPBCS 76-82.

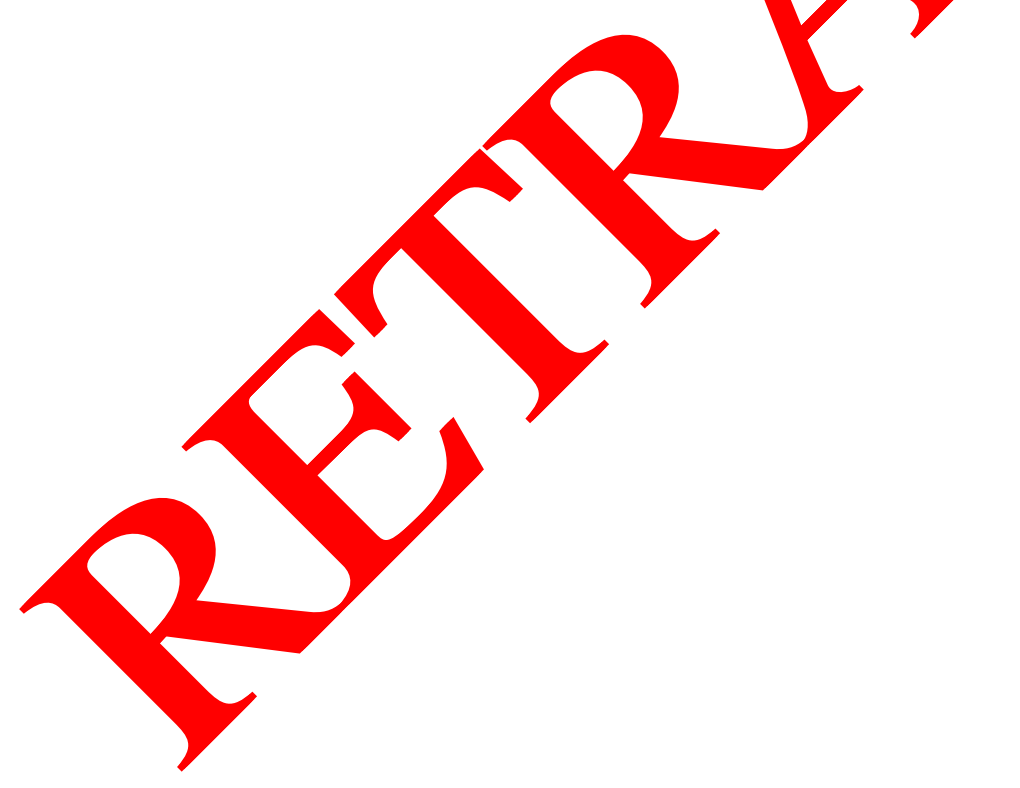

